Academic City University College - Accra Ghana

Society for Multidisciplinary \& Advanced Research Techniques (SMART) Africa

Tony Blair Institute for Global Change

FAIR Forward - Artificial Intelligence for All - Deutsche Gesellschaft für Internationale Zusammenarbeit (GIZ) GmbH

Accra Bespoke Multidisciplinary Innovations Conference (ABMIC)

\title{
Phytochemical Composition and Wound Healing Activity of Azadirachta Indica Seed Extract in Wistar Rats
}

Ibironke A. Ajayi* \& Bolaji S. Odejobi

Industrial Unit, Chemistry Department

Faculty of Science

University of Ibadan, Ibadan, Nigeria

E-mail: frajayi@yahoo.com*

Phone: $+2348075041170 *$ 


\title{
Phytochemical Composition and Wound Healing Activity of Azadirachta Indica Seed Extract in Wistar Rats
}

\author{
Ibironke A. Ajayi*\& Bolaji S. Odejobi
}

\begin{abstract}
The wound healing activity, antimicrobial and phytochemical constituents of Azadirachta indica seeds were investigated. The methanolic extract of $A$. indica was prepared, labeled as AIME and studied for phytochemical constituents, antimicrobial activity on transient flora microorganisms of the skin using standard methods. Wound healing study was conducted on 28 Wistar rats distributed into four groups of seven rats each and incised with wound area of $550 \mathrm{~mm}^{2}$. Rats from Groups 1 and 2 were treated with $15 \%$ and $20 \%$ of AIME respectively, Group 3 with 100 $\%$ ointment (positive control) while Group 4 were left untreated (negative control). The wound healing activity of the prepared ointments were assessed by the rate of wound contraction, wound area and epitheliazation time on every four days interval. The wound effect on the rats (feed intake, growth parameters, change in body weight, and specific growth rate) were also assessed. The phytochemical analysis of AIME revealed the presence of different bioactive compounds such as alkaloid, reducing sugar, cardiac glycosides, flavonoids, terpenoids and sterols in AIME. The two prepared ointments exhibited significant antimicrobial activity on S. aureus, $B$. subtilis and $P$. aeroginosa. The results of the wound healing activity indicated that 15 $\%$ AIME had the most potent wound healing capacity as evident from epitheliazation time ( $15.50 \pm 0.55$ days), followed by its $20 \%$ counterpart with the epitheliazation time of $23.33 \pm 2.73$ days; that of the positive control was $18.00 \pm 1.87$. The activity of the endogenous enzymes on the scar areas were also found to be regulated by the seed extract. The increased wound contraction, the antioxidative and moderate antimicrobial activities of the methanolic extract are indicative of the wound healing potential of $A$. indica seeds.
\end{abstract}

Keywords: Seed extract; phytochemical; antimicrobial; wound healing; epitheliazation period

\section{INTRODUCTION}

The skin protects the body from external environment and it serves as a protective cover for the body mechanism of organs, systems, muscles and nerves found under the skin. Due to the skin's general functions, it is important the skin is restored to its normal state after disruption has occurred on the tissue from an inflicted wound. If the skin was not prone to secondary infections from flora microorganisms like Streptococcus aureus, Pseudomonas aeroginosa and Bacillus subtilis, there would probably be no need to proffer ways in which the wound healing process could be accelerated. Also, depending on the type of wound, affected cells could by extension affect the proper functioning of other cells in the body and then move on to affect the whole body due to the body's interdependent organisation.

Neem seed, Azadirachta indica commonly known in Hausa language as Dogon-yaro, is a widely cultivated plant throughout Nigeria as an ornamental plant. Research work on neem seed and its extract revealed immuno-modulatory, anti-inflammatory, anti-hyperglycaemic, anti-ulcer, antimalaria, anti-fungal and anti-viral properties. Gedunin isolated from neem seed oil has been reported to possess both antifungal and anti-malarial activities. 
The phytochemical analysis of the neem seed revealed the presence of some phytochemicals that have been known to have anti-oxidant and antimalarial properties. This study aims to investigate the presence of these phytochemicals and to investigate the wound healing ability of the methanol extract of $A$. indica seeds.

\section{METHODOLOGY}

\subsection{Extraction of $A$. indica}

A. indica seeds were collected, air dried and crushed to coarse powder with an electric blender before carrying out extraction. $500 \mathrm{~g}$ of the already crushed powdered sample were put in an aspirator bottles. $1 \mathrm{~L}$ of methanol was added to each of the bottles and left at room temperature of about $32 \circ \mathrm{C}$ for five days. The contents were stirred continuously for proper mixing with the solvent and then filtered (Ajayi et al., 2015). The filtrate was distilled to recover the solvent from the oil. The extract was stored in a universal bottle and refrigerated at $4{ }^{\circ} \mathrm{C}$ prior to use.

\subsection{Phytochemical test}

Phytochemical screening was carried out to detect the presence of secondary metabolites such as tannins, saponins, alkaloids flavonoids, reducing sugar and glycoside using the methods described by (Solomon et al., 2013). All determinations were done in triplicates.

\subsection{Pharmacological study of $A$. indica seed extracts}

2.3.1 Antimicrobial activity assay

The antimicrobial activity of the seed extract was evaluated against a few pathogenic bacterial such as Staphylococcus aureus, Bacillus subtilis and Pseudomonas aeroginosa. The pure bacterial strains were obtained from the Department of Pharmaceutical Microbiology, University of Ibadan, Ibadan, Nigeria. The bacterial strains were cultured overnight at $37{ }^{\circ} \mathrm{C}$ in nutrient agar.

\subsubsection{Minimum inhibitory concentrations of seed extract}

Minimum Inhibitory Concentration (MIC) is defined as the lowest concentration of the extracts that inhibit the visible growth on agar surface or turbidity in microwell broth. Minimum inhibitory concentrations both for bacterial and fungal strains were measured as reported in literature by (Sarker et al., 2007).

\subsection{Experimental animals}

Wistar rats between the weights of $42-150 \mathrm{~g}$ were used for this research work. The rats were obtained from University of Ibadan, Ibadan animal breeding house. The rats were left to acclimatize in the experimental house in the University of Ibadan for seven days. The study was done in the experimental house of Veterinary Anatomy Department, University of Ibadan, Ibadan, Nigeria.

\subsection{Wound excision model}

The wistar rats were injected with $0.2 \mathrm{~mL}$ ketamine hydrochloride anaesthesia based on the weight of the rats. After the numbness has been induced, the fur of the rats was scrapped off on the lateral right side of the animal using a scissors. A wound area of $2.65 \mathrm{~cm}$ diameter was impressed on the rats few meters away from the hind limb. The entire thickness of the skin was then excised using scalpels, toothed forceps and a pointed scissors. Methylated spirit was used as antiseptic for the excised region. 
The wound were undressed and open to the environment. The weight of the rats was recorded as weight for day zero. The rats were returned to their cages and provided with water and feed after they had recovered from the effect of the anaesthesia.

\subsection{Preparation of ointments}

$3.75 \mathrm{~g}$ of $A$. indica extract was weighed with an analytical balance and poured into a $25 \mathrm{ml}$ standard flask. This was then made up to the mark with paraffin oil preparing $15 \%(\mathrm{w} / \mathrm{v})$ concentration of the extract. $5.0 \mathrm{~g}$ of $A$. indica extract was also weighed using an analytical balance and transferred into a $25 \mathrm{ml}$ flask. This was then made up to the mark with paraffin oil preparing $20 \%(\mathrm{w} / \mathrm{v})$ concentration of the oil extract.

\subsection{Wound treatment}

The rats in the different groups were treated by applying the prepared ointment using a cotton bud on the excised wound. This treatment was done every day for 24 days until the epithelisation stage of the animals was reached. The process was repeated for groups 2 animals treated with $20 \%$ ointment. Group 3 animals were treated with $100 \%$ paraffin oil while group 4 was left untreated for 24 days.

\section{7 Wound healing activity}

The diameter of the wound for the rat in each group was measured using a ruler. The percentage wound contraction was measured using the formula:

$\frac{I A-F A}{I A} \times 100$

Where FA is the final area and IA is initial area.

The percentage wound contraction was measured on the days 4, 8, 12, 16, 21 and 24 (Sharma et al., 2010).

\subsection{Growth parameters}

\subsubsection{Biomass gain \%}

Biomass gain $=\frac{w t-w o}{\text { wo }} \times 100$

Wo \& Wt are live weight at the time of starting the experiment and at the end of the experiment (Sharma et al., 2010).

Feed conversion ratio (FCR)

$\mathrm{FCR}=\frac{\text { feed ingested }}{\text { weight gain }}$

\subsubsection{Specific growth rate}

The initial and final weights of the rats in each group were measured individually. Specific growth rate was determined according to the formulae below:

$\operatorname{SGR}(\%)=\frac{\operatorname{In}[\text { final means biomass }(\mathrm{g})]-\operatorname{In}[\text { initial means biomass }(\mathrm{g})]}{\text { time interval }(\text { days })}$

(Sharma et al., 2010). 


\subsubsection{Epithelisation time}

The epithelisation time for each of the rats was noted and recorded. Epithelisation time is the time it took the wound to heal completely.

\subsection{Histological study}

The skin tissues were collected on the $24^{\text {th }}$ day ofthe experiment from all the four groups of animals and processed for histological study to determine the pattern of lay-down for collagen. The skin specimens from the treated animals were collected in $10 \%$ buffered formalin and subjected to sectioning; $6 \mathrm{~mm}$ thickness sections were stained with hematoxylin and eosin. The stained slides were visualized for histological changes under a light microscope (Anderson, 1980).

\subsection{Endogenous enzymes}

The sample was homogenised in phosphate buffer $(0.1 \mathrm{~m} \mathrm{pH} 7.4)$ using homogenizer. The homogenates were centrifuged at $10.000 \mathrm{rpm}$ at $4{ }^{\circ} \mathrm{C}$ for 10 mins using table top centrifuge and then the supernatants were stored in a deep freezer.Assay of superoxide dismutase (SOD), reduced glutathione and catalase.

\subsection{Statistical analysis}

Statistical analysis was performed on each group $n=7$ and ANOVA test (IBM SPSS statistical 20.0 software) was used to compare the mean value of each treatment. Significant differences between the means of parameters were determined using the Duncan $T$ test $(P<0.05)$. The results represented means and standard deviation of 7 replicate determinations. The data were expressed as means \pm SD for four replicates and were subjected to one way analysis of values. The values were then statistically considered.

\section{RESULTS}

Table 1: Phytochemical constituents of the seed extract

\begin{tabular}{lllll}
\hline S/N & TEST & Group 1 & Group 2 & Group 3 \\
\hline 1 & Flavonoid & + & + & - \\
2 & Reducing sugar & + & + & - \\
3 & Alkanoid & + & + & - \\
4 & Carbohydrate & + & + & - \\
5 & Cardicglycosidic & + & + & - \\
6 & Phenol & - & - & - \\
7 & Saponin & + & + & + \\
8 & Sterol & - & + & - \\
9 & Tanin & + & + & - \\
10 & Terpenoid & &
\end{tabular}

Group 1: A. indica seed at $15 \%(w / v)$ concentration; Group 2: A. indica seed at $20 \%(w / v)$ concentration; Group 3: Control (ointment alone). 
Table 2: Antimicrobial activity of $A$. indica against flora organisms

Zone of inhibition in diameter ( $\mathrm{mm}$ )

Test organisms Concentration of $A$. indica extract $(\mathrm{mg} / \mathrm{mL})$

\begin{tabular}{llllllll} 
& Methanol & 200.0 & 100.0 & 50.00 & 25.0 & 12.50 & Gentamicin \\
& & 0 & 0 & & 0 & & \\
\hline S. aureus & - & 24 & 20 & 18 & 14 & 10 & 38 \\
B. subtilis & - & 20 & 18 & 14 & 12 & 10 & 36 \\
P. aeroginosa & - & 26 & 22 & 18 & 14 & 10 & 34 \\
\hline
\end{tabular}

Methanol is the negative control; gentamicin is the positive control; - indicates the absence antimicrobial activities.

Table 3: Minimal inhibitory concentration (MIC) of $A$. indica in $\mathrm{mg} / \mathrm{m} \mathrm{L}$

\begin{tabular}{lllll} 
Test organism & \multicolumn{4}{c}{ Concentration of the extract $(\mathrm{mg} / \mathrm{mL})$} \\
\cline { 2 - 5 } S. aureus & 200 & 100 & 50 & 25 \\
B. subtilis & - & - & - & \pm \\
$P$. aeroginosa & - & - & - & + \\
\hline - indicates no growth of organism; + indicates the growth of organism; \pm not determined
\end{tabular}

Table 4: Wound contraction (\%)

\begin{tabular}{lllll}
\hline Day & Group 1 & Group 2 & Group 3 & Group 4 \\
\hline Day 4 & $12.40 \pm 6.80^{\mathrm{ab}}$ & $3.46 \pm 0.00^{\mathrm{b}}$ & $26.11 \pm 14.51^{\mathrm{a}}$ & $21.99 \pm 15.95^{\mathrm{a}}$ \\
Day 8 & $75.30 \pm 3.57^{\mathrm{a}}$ & $72.00 \pm 0.00^{\mathrm{ab}}$ & $56.65 \pm 12.75^{\mathrm{abc}}$ & $38.44 \pm 16.79^{\mathrm{bc}}$ \\
Day 12 & $94.39 \pm 0.90^{\mathrm{a}}$ & $88.28 \pm 3.64^{\mathrm{a}}$ & $94.17 \pm 5.65^{\mathrm{a}}$ & $90.86 \pm 0.00^{\mathrm{a}}$ \\
Day 16 & $100.00 \pm 0.00^{\mathrm{a}}$ & $97.35 \pm 3.53^{\mathrm{a}}$ & $98.01 \pm 2.87^{\mathrm{ab}}$ & $95.18 \pm 0.47^{\mathrm{b}}$ \\
Day 20 & $100.00 \pm 0.00^{\mathrm{a}}$ & $98.71 \pm 0.00^{\mathrm{ab}}$ & $100.00 \pm 0.00^{\mathrm{b}}$ & $98.94 \pm 0.32^{\mathrm{bc}}$ \\
Day 24 & $100.00 \pm 0.00^{\mathrm{a}}$ & $100.00 \pm 0.00^{\mathrm{a}}$ & $100.00 \pm 0.00^{\mathrm{a}}$ & $99.85 \pm 0.00^{\mathrm{a}}$ \\
\hline
\end{tabular}

Group 1: A. indica seed at $15 \%(w / v)$ concentration; Group 2: A. indica seed at $20 \%(\mathrm{w} / \mathrm{v})$ concentration; Group 3: Positive control (ointment only); Group 4: Negative control (no treatment). Values are expressed as mean \pm SD for groups of seven animals each. Data with different superscript letters along the same column are significantly different $(p<0.05)$ using one ANOVA followed

Table 5: Effect of wound and seed extract on the biomass gain of the model rats

\begin{tabular}{ll}
\hline Groups & BMG \% \\
\hline Group 1 & $55.53 \pm 26.49^{\mathrm{a}}$ \\
Group 2 & $28.60 \pm 14.36^{\mathrm{bc}}$ \\
Group 3 & $47.88 \pm 6.21^{\mathrm{ab}}$ \\
Group 4 & $41.35 \pm 21.51^{\mathrm{abc}}$ \\
\hline
\end{tabular}


Group 1: A. indica seed at $15 \%$ (w/v) concentration; Group 2: A. indica seed at $20 \%(\mathrm{w} / \mathrm{v})$ concentration; Group 3: Positive control (ointment only); Group 4: Negative control (no treatment); BMG: Biomass gain per group of the animal. Values are expressed as mean \pm SD for groups of seven animals each. Data with different superscript letters along the same column are significantly different $(p<0.05)$ using one ANOVA followed by Dunnett's test).

Table 6: Feed conversion ratio (FCR)

\begin{tabular}{lllllll}
\hline Groups & D4 & D8 & D12 & D16 & D20 & D24 \\
\hline Group 1 & 27.30 & 2.87 & 13.21 & 12.02 & -5.85 & 17.14 \\
Group 2 & 13.16 & 5.26 & 16.92 & 5.39 & -17.83 & 5.00 \\
Group 3 & 5.07 & 12.97 & 4.41 & 20.2 & 7.07 & 8.83 \\
Group 4 & -2.49 & 3.57 & 7.70 & 7.61 & 16.05 & 6.86 \\
\hline
\end{tabular}

Group 1: A. indica seed at $15 \%(\mathrm{w} / \mathrm{v})$ concentration; Group 2: A. indica seed at $20 \%(\mathrm{w} / \mathrm{v})$ concentration; Group 3: Positive control (ointment only); Group 4:Negative control (no treatment).

Table 7: Specific Growth Rate (SGR)

\begin{tabular}{ll}
\hline Groups & SGR \\
\hline Group 1 & 2.08 \\
Group 2 & 1.25 \\
Group 3 & 1.63 \\
Group 4 & 1.41 \\
\hline
\end{tabular}

Group 1: A. indica seed at $15 \%(\mathrm{w} / \mathrm{v})$ concentration; Group 3: A. indica seed at $20 \%(\mathrm{w} / \mathrm{v})$ concentration; Group 4: Positive control (ointment only); Group 4: Negative control (no treatment).

Table 8: Epithelialization time (Days)

\begin{tabular}{ll}
\hline Groups & E. Time \\
\hline Group 1 & $15.50 \pm 0.55^{\mathrm{c}}$ \\
Group 2 & $23.33 \pm 2.73^{\mathrm{a}}$ \\
Group 3 & $18.00 \pm 1.87^{\mathrm{b}}$ \\
Group 4 & $24.00 \pm 1.78^{\mathrm{a}}$ \\
\hline
\end{tabular}

Group 1: A. indica seed at $15 \%$ (w/v) concentration; Group 2: A. indica seed at $20 \%$ (w/v) concentration; Group 3: Positive control (ointment only); Group 4: Negative control (no treatment).

Table 9: Endogenous Enzymes

\begin{tabular}{llll}
\hline Groups & GSH & SOD & CAT \\
\hline Group 1 & 52.60 & 72.52 & 61.78 \\
Group 2 & 66.32 & 92.53 & 39.75 \\
Group 3 & 44.90 & 97.57 & 90.22 \\
Group 4 & 34.54 & 85.07 & 17.27 \\
\hline
\end{tabular}

Group 1: A. indica seed at $15 \%$ (w/v) concentration; Group 2: A. indica seed at $20 \%(\mathrm{w} / \mathrm{v})$ concentration; Group 3: Positive control (ointment only); Group 4: Negative control (no treatment); SOD: Superoxide Dimutase; GSH: Glutathione; CAT: Catalase. 
Table 10: Histology examination

\begin{tabular}{ll}
\hline GROUPS & Histological examination of the skin scar area \\
\hline Group 1 & $\begin{array}{l}\text { There is a discontinuity of the epidermis (thick arrow). There are } \\
\text { numerous sebaceous glands and hair follicles in the dermis (star). }\end{array}$ \\
Group 2 & $\begin{array}{l}\text { The epidermis (thick arrow) is intact. Dermis appears normal with } \\
\text { numerous hair follicles and sebaceous glands (arrows). }\end{array}$ \\
Group 3 & $\begin{array}{l}\text { The epidermis (thick arrow) is intact and thick. The dermis (star) } \\
\text { contains numerous hair follicles (thin arrows) enmeshed within dense } \\
\text { fibrous connective tissue. }\end{array}$ \\
Group 4 & $\begin{array}{l}\text { The epidermis (thick arrow) is thin and intact. Dermis appears normal } \\
\text { with hair follicles and sebaceous glands (arrows) }\end{array}$ \\
\hline
\end{tabular}

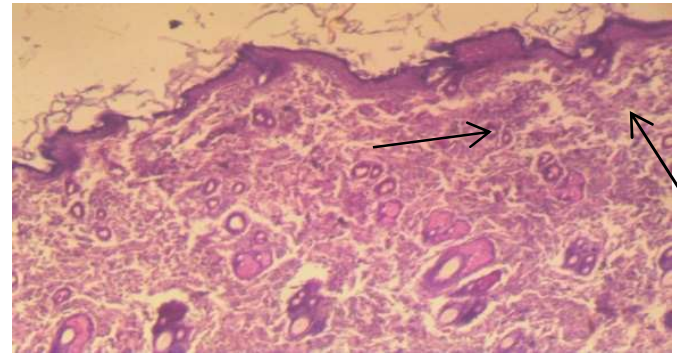

Group 1: A. indica seed at $15 \%(\mathrm{w} / \mathrm{v})$ concentration $(\mathrm{w} / \mathrm{v})$ concentration

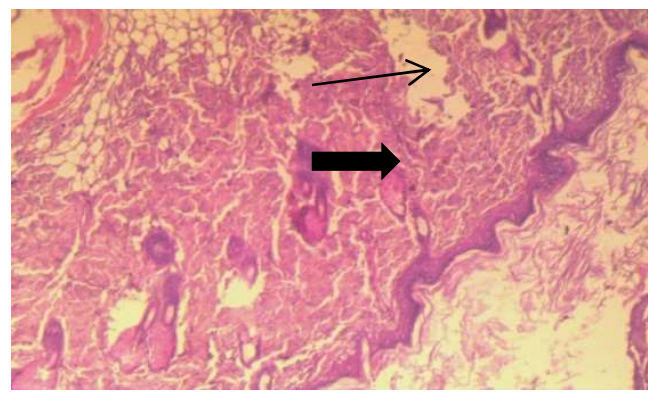

Group 3: Positive control (ointment only) treatment)
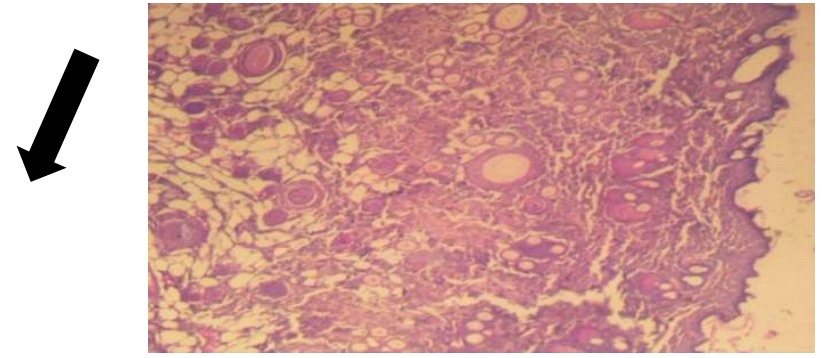

Group 2:A. indica seed at $20 \%$

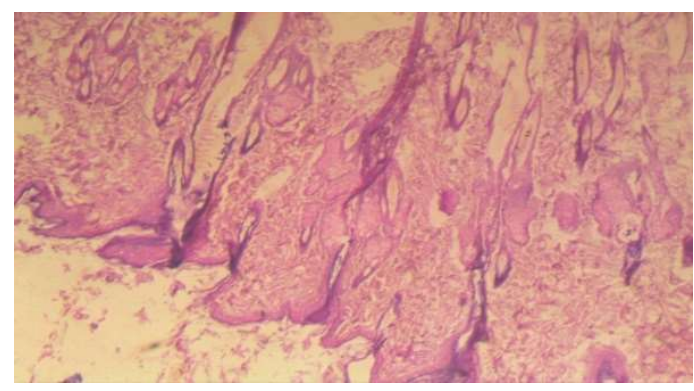

Group 4: Negative control (no

Fig 1: Photomicrograph of the skin of rats from groups 1-4 
DAY 4

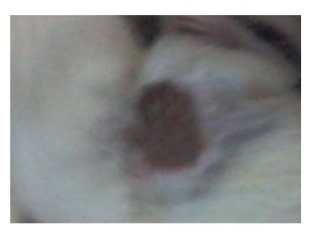

Group 1

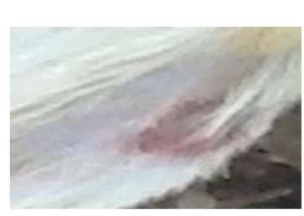

Group 1

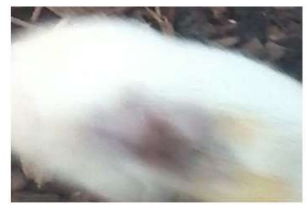

Group 1

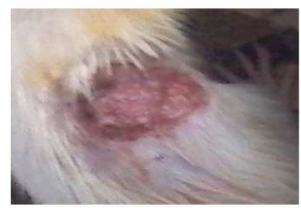

2

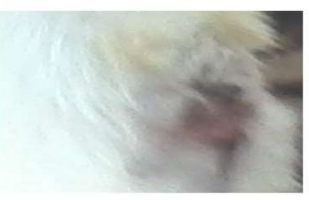

2

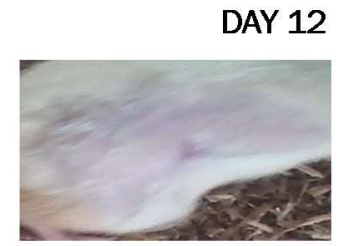

2

\section{DAY 16}

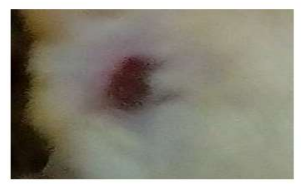

Group 1

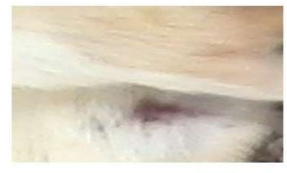

Group 1

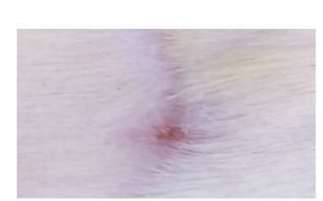

Group 1

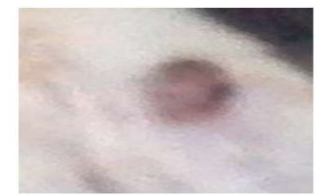

3

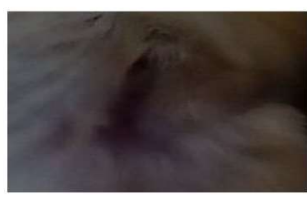

3

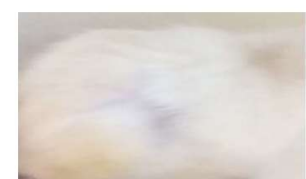

2

DAY 20

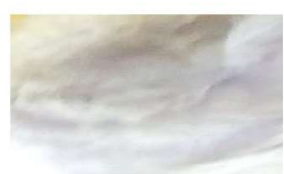

3

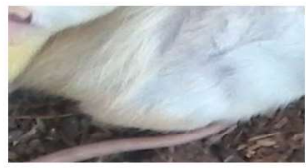

3

2

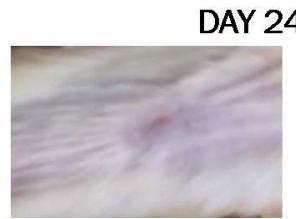

2

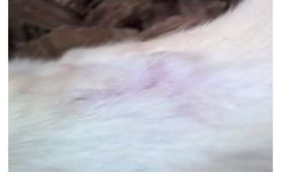

3

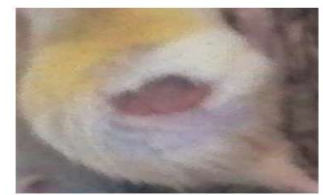

4

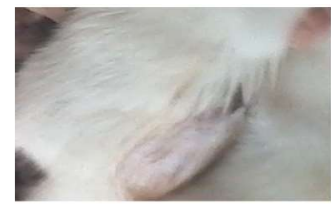

4

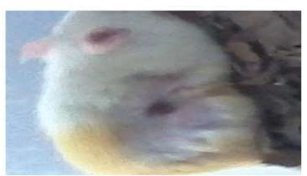

4

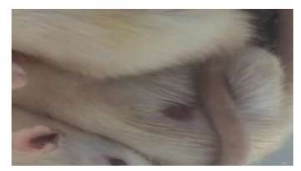

4

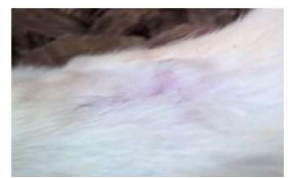

4

Fig 2: Pictures showing wound healing pattern of rats from groups 1-4 over 24 days 


\section{DISCUSSION}

The phytochemical analysis was carried out on the ointment used in treating the animals. Table 1 shows that the phytochemical constituents were either present or absent in the ointment. Flavonoid is present in $A$. indica likewise reducing sugar, alkanoids, carbohydrate, cardiac glycosidic, sterols, terpenoids are present in both $A$. indica $15 \%$ and $20 \%$ ointment formulations. These compounds have been discovered to be active against potentially significant pathogens including those that are responsible for enteric infections (Owolabi et al., 2007).Flavonoids are now recognized as possessing an array of bioactivities with several mechanisms relevant to potential reductions in the pathogenesis of chronic diseases (Meskin et al., 2008).

The result of the antimicrobial activity of $A$. indica was summarised in table 2 . Methanol the negative control showed no antimicrobial activity against the three test microganisms $S$. aureus, $B$. subtilis and $P$. aeroginosa. The highest zone of inhibition of $24 \mathrm{~mm}$ diameter against $S$. aureus microorganism was recorded at the highest concentration of the A. indica extract at $200 \mathrm{mg} / \mathrm{mL}$. This value is not far from the positive control gentamicin with its zone of inhibition at $38 \mathrm{~mm}$. The analysis revealed $20 \mathrm{~mm}$ zone of inhibition at $100 \mathrm{mg} / \mathrm{mL}$ of the extract, $18 \mathrm{~mm}$ zone of inhibition at $50 \mathrm{mg} / \mathrm{mL}, 14 \mathrm{~mm}$ zone of inhibition at $25 \mathrm{mg} / \mathrm{mL}$ and $10 \mathrm{~mm}$ at $12.50 \mathrm{mg} / \mathrm{mL}$ of the extract. Anti-microbial activity was recorded for all the test concentrations. This indicates that $A$. indica can prevent the growth of $S$. aureus on the wound surface even at low concentrations, as low as $12.50 \mathrm{mg} / \mathrm{mL}$ of the extract and also at very high concentration. However, for maximum prevention of $S$. aureus on the wound surface and for fast wound healing activity, high concentrations of the extract should be used.

The highest zone of inhibition of $20 \mathrm{~mm}$ diameter was observed against $B$. subtilis microorganism at the highest concentration of the $A$. indica extract at $200 \mathrm{mg} / \mathrm{mL}$. This value is not far from the positive control gentamicin with its zone of inhibition at $36 \mathrm{~mm}$. The analysis revealed $18 \mathrm{~mm}$ zone of inhibition at $100 \mathrm{mg} / \mathrm{mL}$ of the extract, $14 \mathrm{~mm}$ zone of inhibition at $50 \mathrm{mg} / \mathrm{mL}, 12 \mathrm{~mm}$ zone of inhibition at concentration $25 \mathrm{mg} / \mathrm{mL}$ and $10 \mathrm{~mm}$ zone of inhibition at a concentration of $12.50 \mathrm{mg} / \mathrm{mL}$ of the $A$. indica extract. Therefore, for maximum result and for good wound healing activity, the concentration of the extract should be at $200 \mathrm{mg} / \mathrm{mL}$ of the extract. It can also impede the growth of $B$. subtilis at low concentrations.

The highest zone of inhibition of $26 \mathrm{~mm}$ diameter was observed at the highest concentration of the $A$. indica seed at $200 \mathrm{mg} / \mathrm{mL}$ against $P$. aeroginosa microorganism. The positive control gentamicin has a zone of inhibition of $34 \mathrm{~mm}$. The analysis revealed $22 \mathrm{~mm}$ zone of inhibition at $100 \mathrm{mg} / \mathrm{mL}$ of the extract, $18 \mathrm{~mm}$ zone of inhibition at $50 \mathrm{mg} / \mathrm{mL}, 14 \mathrm{~mm}$ zone of inhibition at $25 \mathrm{mg} / \mathrm{mL}$ of the extract and $10 \mathrm{~mm}$ zone of inhibition at $12.50 \mathrm{mg} / \mathrm{mL}$ of the extract. This revealed that the extract is good at concentrations as low as $12.50 \mathrm{mg} / \mathrm{mL}$ for inhibiting the growth of $P$. aeroginosa. However, higher concentrations of the extract should be used for maximum wound healing activity. At concentration of $200 \mathrm{mg} / \mathrm{mL}, A$. indica showed the highest antimicrobial activity against $P$. aeroginosa microorganism, then $S$. aureus lastly $B$. subtilis microorganism.

The minimum inhibitory concentration of $A$. indica against flora microorganism as summarised in table 3 showed that; at $200 \mathrm{mg} / \mathrm{mL}$ concentration of the extract ointment, no growth of the organism S. aureus was observed also at concentration $100 \mathrm{mg} / \mathrm{mL}$ and $50 \mathrm{mg} / \mathrm{mL}$. However, it will not inhibit the growth of the organism at a concentration of $25 \mathrm{mg} / \mathrm{mL}$ as the result was not determined. 
At concentrations below $50 \mathrm{mg} / \mathrm{mL}$ the extract ointment will not inhibit the growth of the microorganism. This showed that it has a (MIC) of $50 \mathrm{mg} / \mathrm{mL}$ against $\mathrm{S}$. aureus. Hence, for maximum wound healing ability, the extract ointment should not be used at concentrations below $50 \mathrm{mg} / \mathrm{mL}$. B. subtilis was inhibited at a concentration of $200 \mathrm{mg} / \mathrm{mL}, 100 \mathrm{mg} / \mathrm{mL}$ and $50 \mathrm{mg} / \mathrm{mL}$ but at a concentration of $25 \mathrm{mg} / \mathrm{mL}$, it showed the growth of the organism which indicates that $A$. indica has a (MIC) of $50 \mathrm{mg} / \mathrm{m}$ L against $B$. subtilis and so will not inhibit the growth of the microorganism at concentrations below $200 \mathrm{mg} / \mathrm{mL}$. A. indica can inhibit the growth of $P$. aeroginosa at concentrations of $200 \mathrm{mg} / \mathrm{mL}, 100 \mathrm{mg} / \mathrm{mL}$ and $50 \mathrm{mg} / \mathrm{mL}$ but at a concentration of $25 \mathrm{mg} / \mathrm{mL}$, the result was undetermined. This indicates that $A$. indica has a MIC of $50 \mathrm{mg} / \mathrm{mL}$ against $P$. aeroginosa and so concentrations below $50 \mathrm{mg} / \mathrm{mL}$ should not be used for maximum wound healing ability.

The biomass gain of the model rats is summarized in table 5. The higher the biomass gain of the rats, the higher the growth rate of the rats. Group 1 recorded the highest biomass gain at $55.53 \pm 26.49 \%$. Group 1 with the highest biomass is the most effective in treating the animals as it gave a high value of the biomass.

The specific growth rate is summarised in table 7 . The specific growth rate is an increase in mass per the interval of days for the experiment. Group 1 had the highest SGR of 2.08 with group 2, group 3 and group 4 at SGR values of 1.25, 1.63 and 1.41 respectively. The increase in weight can be attributed to the efficient healing ability of the extract.

Epithelialization is the formation of granulation tissue unto an open wound. Epithelialization denotes the formation of epithelia cells over the open wound. The epithelialization time for the rats is summarised in table 8. The smaller the epithelialization time, the faster the wound healing process.Group 1 has the lowest value at $15.50 \pm 0.55$ days. This is an indication that group 1 animals healed the fastest and it proves how effective the formulation is in treating the animals. Endogenous enzymes examination indicates the presence of scavenging radicals due to the presence of oxidative stress on the tissue surface (Table 9). Histopathological analysis result (Table 10) of the skin of the rats of group 1 revealed that the epidermis (thick arrow) is intact. Dermis appears normal with numerous hair follicles and sebaceous glands (arrows).

\section{CONCLUSION}

In conclusion, the $15 \%(\mathrm{w} / \mathrm{v})$ concentration of the extract proved to be more effective in healing the wound compared to the $20 \%(\mathrm{w} / \mathrm{v})$ concentration due to the free radical scavenging ability of the formulation at this concentration.

\section{Acknowledgement}

The authors wish to acknowledge the Department of Chemistry, Faculty of Science and Pathology Department, Faculty of Veterinary both of University of Ibadan, Ibadan, Nigeria for their facilities. 


\section{REFERENCES}

1. Ajayi I.A., Raji, A.A., and Umeh, A.R. (2015). Investigation into the wound healing activity of Monodora myristica and Monodora tenuifolia seed extracts in wistar rats. American Chemical Science Journal. 4: 1-16.

2. Anderson K.R., Sutton M.G., Lie J. T., O'Brien P.C. and Frye R.I. (1980). Histopathological specification of hypertropic obstructive cardiomyopathy: myocardial fibre disarray and myocardial fibrosis. British Heart Journal. 44: 433-443.

3. MeskinM.S., BidlackW.R. and Randolph R.K. (2008).Phytochemicals : aging and health. Boca Raton: Taylor \& Francis Group, LLC.pp.21.

4. Owolabi O. J., Omogbai E. and Obasuyi O. (2007). Antifungal and antibacterial activities of the ethanolic and aqueous extracts of Kigelia africana (Bignoniaceae) stem bark. African Journal of Biotechnology. 6: 1677-1680

Wound Healing. 5: 230-241.

5. Sarkar S., Banerjee S., Erikson P.G. and Catuneanu O. (2005). Microbial mat control on siliciclastic precambrian sequence stratigraphy architecture; examples for India. Sedimentory Geology. 176: 195-209.

6. Sharma B.B., Saha R.K.and Saha H. (2014). Effects of feeding detoxified rubber seed meal an growth performance and haematological indices of Labeorohita (Hamilton) fingerlings. Animal Feed Science and Technology. 3: 8-17.

7. Solomon C.U., Arukwe U. and Onuoha I. (2013). Preliminary phytochemical screening of different solvent extracts of stem bark and roots of Dennetia tripetalaG. Barker. Asian Journal of Plant Science.3: 10-13. 